\title{
Association between depression and development of coronary artery disease: pathophysiologic and diagnostic implications
}

This article was published in the following Dove Press journal:

Vascular Health and Risk Management

I5 March 20I I

Number of times this article has been viewed

\section{Carlos V Serrano Jr' \\ Karina Tiemi Setani ${ }^{2}$ \\ Erica Sakamoto ${ }^{2}$ \\ Anna Maria Andrei ${ }^{3}$ \\ Renério Fraguas ${ }^{4}$}

'Heart Institute (InCor), ${ }^{2}$ Medical School, University of São Paulo, Brazil; ${ }^{3}$ Albert Einstein Hospital, São Paulo, Brazil; ${ }^{4}$ Department and Institute of Psychiatry, Medical School, University of São Paulo, Brazil
Correspondence: Carlos V Serrano Jr Heart Institute (InCor HCFMUSP), Avenida Enéas de Carvalho Aguiar, 44 Building II, 2nd Floor, Room 12 , São Paulo, SP 05403-90I, Brazil Tel +55 I| 30695058 $\mathrm{Fax}+55$ || 30883809 Email carlos.serrano@incor.usp.br

\begin{abstract}
Depression and coronary artery disease (CAD) are both extremely prevalent diseases. In addition, compromised quality of life and life expectancy are characteristics of both situations. There are several conditions that aggravate depression and facilitate the development of CAD, as well as provoke a worse prognosis in patients with already established CAD: inferior adherence to medical orientations (medications and life style modifications), greater platelet activation and aggregation, endothelial dysfunction, and impaired autonomic dysfunction (lowered heart rate variability). Recent literature has shown that depression alone is becoming an independent risk factor for cardiac events both in primary and secondary prevention. As the diagnosis of depression in patients with heart disease is difficult, due to similarities of symptoms, the health professional should perform a careful evaluation to differentiate the clinical signs of depression from those related with general heart diseases. After a myocardial infarction, depression is an independent risk factor for mortality. Successful therapy of depression has been shown to improve patients' quality of life and cardiovascular outcome. However, multicentric clinical trials are needed to support this inference. A practical liaison between qualified professionals is necessary for the better management of depressed patients with excess risk in developing CAD. Accordingly, pathophysiological and clinical implications between depression and CAD are discussed in this article.
\end{abstract}

Keywords: depression, coronary artery disease, behavioral disorders, prognosis

\section{Introduction}

It is well known that depression is highly prevalent among patients with coronary artery disease (CAD) at approximately three times greater than in the general population. ${ }^{1}$ In addition, depression behaves as a risk factor for the development of CAD, and worsens outcome when present in patients with established CAD. ${ }^{2,3}$ The prevalence of major depression in patients with CAD is approximately $20 \%,{ }^{4,5}$ making depression a condition affecting millions of patients with CAD annually. Although the mechanisms underlying this connection remain unclear, it has been suggested that depression is associated with both physiological and psychosocial changes that are deleterious to the cardiovascular system. ${ }^{6}$

Published studies suggest that depression is a particularly strong psychosocial predictor of CAD onset and progression. As the link between depression and CAD has become increasingly predictable and established between specialists, pharmacologic and nonpharmacologic interventions on depression in patients with heart disease have come into practice. Depression has a harmful effect on the cardiovascular system. Supposedly, treatment of depression should lessen its negative prognostic outcome. ${ }^{7}$ 
A very vital aspect of continued therapeutic advances in this arena have shown a persuasive link between successful management of depression in patients with CAD and a reduction in cardiovascular events. However, the investigations addressing this hypothesis have demonstrated a variety of conclusions..$^{8,9}$

Outstandingly, besides depression, disorders of behavior such as irritability, anger, and hostility are also associated with the major clinical events of CAD. ${ }^{10}$

The purpose of this article is to review some of the most important pathophysiological and clinical aspects in the field of depression and CAD. In essence, the authors propose to discuss the cause-effect association between depression and $\mathrm{CAD}$ and the perplexity of detecting depression in a patient with CAD. In addition, other situations of emotional disorders are approached as to also evaluate their associations with CAD.

\section{Current status of the mechanistic pathways between depression and CAD}

Established coronary risk factors such as hypercholesterolemia, hypertension, diabetes, obesity, and smoking are bound to accumulate in depressed patients. ${ }^{11}$ However, in 1987, a meta-analysis of studies published between 1945 and 1985, about psychosocial predictors of CAD concluded that depression is the main psychosocial risk factor for cardiovascular disease. ${ }^{5}$

A number of reasonable biobehavioral mechanisms are suggested to underlie the relationship between depression and CAD: treatment adherence and lifestyle factors such as smoking, heavy alcohol use, and physical inactivity. Depression foresees reduced adherence to prescribed regimens. No adherence to recommended lifestyle changes and medication regimes itself is associated with a poor outcome for CAD patients, ${ }^{12}$ suggesting that adherence may be a mechanism linking depression and CAD outcomes. Depression is also related with increased rates of smoking and may lower the success of smoking cessation programs in CAD patients. ${ }^{13}$ Depression also is associated with increased alcohol intake and physical inactivity. ${ }^{14}$

Other mechanisms linking depression and heart disease include autonomic imbalance, platelet-endothelial interaction, neurohumoral activation, inflammation, and polymorphism in the serotonin gene transport. ${ }^{15}$

The mechanistic pathways relating depression and CAD are summarized in Figure 1.

\section{Dysregulation of the autonomic nervous system}

Autonomic imbalance, characterized by disproportionate sympathetic activation and/or altered vagal activation,

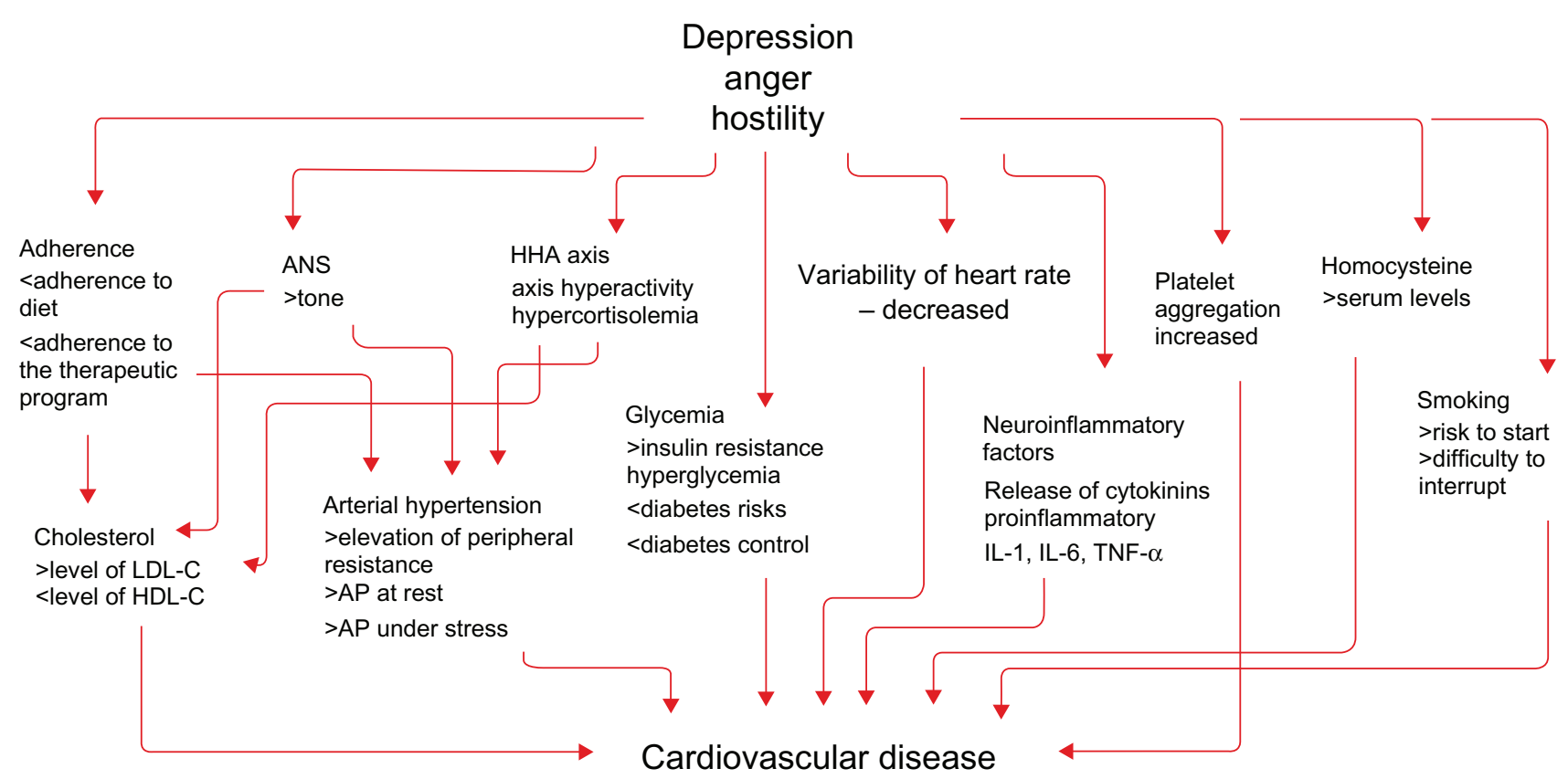

Figure I Pathophysiologic mechanisms between depression, anger and hostility, and cardiovascular disease. ${ }^{10}$

Abbreviations: ANS, autonomous nervous system; HPA, hypothalamus-pituitary-adrenal; LDL-C, low density lipoprotein cholesterol; HDL-C, high-density lipoprotein cholesterol; AP, arterial blood pressure; IL, interleukin; TNF, tumor necrosis factor. 
are associated with higher incidence of morbidity and mortality. ${ }^{16}$

The relationship between depression and heart rate variability is explained by the effect of depression in the balance between the sympathetic and parasympathetic systems, which, in turn, affects the cardiac pacemaker. Carney et $\mathrm{al}^{17}$ reported that patients with CAD and depression had significantly less heart rate variability than non-depressed cardiac patients. Absence of heart rate variability understands a sympatheticvagal disparity and is a risk factor for ventricular arrhythmias and sudden cardiac death in patients with cardiovascular disease. ${ }^{18}$ This situation is aggravated among depressed patients that suffer a myocardial infarction, which suggests that low heart rate variability may facilitate the adverse outcome of depression on survival after a myocardial infarction.

\section{Platelet activation and endothelial dysfunction}

The association between depression and CAD may also be mediated by changes in platelet activation. Platelets play a central role in homeostasis and the development of atherosclerosis, thrombosis, and acute coronary syndromes by means of its interaction with subendothelial components of affected vessels and with coagulation factors.

Enhanced platelet reactivity is common within depressed patients. Plasma levels of platelet factor IV and betathromboglobulin, markers of platelet activation, are higher in depressed patients with ischemic heart disease than in nondepressed patients with ischemic heart disease and control patients. ${ }^{19}$

Interestingly, in a substudy of the Sertraline AntiDepressant Heart Attack Randomized Trial, depressed myocardial infarction patients that were treated with sertraline, a selective serotonin reuptake inhibitor, presented substantially less activation of platelets and endothelial cells. ${ }^{20}$

Endothelial dysfunction, denoted by altered flowmediated dilation of the brachial artery, can be also present in depressed patients that do not present traditional atherosclerotic risk factors. $^{21}$

\section{Hypothalamic-pituitary-adrenocortical (HPA) and sympathetic adrenal medullary (SAM) activation}

High blood levels of cortisol induces endothelial injury which, in turn, mediates hypertension and atherosclerosis. Sympathoadrenal activation leads to catecholamine production and subsequent tachycardia, vasoconstriction, and platelet activation. A mechanism by which a worse clinical outcome can be installed in depressed patients is the excessive stimulation of the HPA and SAM systems. ${ }^{22}$

\section{Inflammatory markers}

There is some preliminary evidence suggesting that alterations in immune functioning and inflammation may be the link between depression and CAD, however, it is not clear that patients with CAD have a greater inflammation status if depression exists. ${ }^{23}$ Depressed patients have higher levels of C-reactive protein and inflammatory cytokines, which play important roles in atherogenesis. ${ }^{24} \mathrm{~A}$ recent investigation evaluated direct associations between levels of depression and C-reactive protein concentrations in patients that suffered a myocardial infarction. ${ }^{25}$

Since vagal tone inhibits the secretion of inflammatory cytokines, treatments that stimulate the vagus nerve such as exercise, biofeedback, and meditation may have favorable anti-inflammatory consequences. ${ }^{26}$

\section{Genetic polymorphism in the serotonin transport promoter region gene}

Serotonin transport promoter region gene (5-HTTLPR) exists in two forms, a long one and a less-effective short one that appears to predispose to depression. Patients with myocardial infarction that possessed one or both of their alleles of this short gene were more likely to become depressed and to have subsequent cardiac events. ${ }^{27}$

\section{Depression: difficult to diagnose within patients with CAD}

The diagnosis of depression in the presence of heart disease is hampered by the similarity of symptoms in both conditions such as lack of energy, lack of appetite, fatigue, insomnia, and difficulty concentrating. ${ }^{28}$ Screening assessment for depressive manifestations is useful to identify patients who may require further stratification and management. ${ }^{29}$ The opportunity to screen for and treat depression in cardiac patients should not be missed, as effective depression treatment may reduce morbidity and mortality. If positive screening results are established, evaluation by qualified professionals is preferred.

Medical literature has shown that up to $20 \%$ of patients with recent myocardial infarction meet the Diagnostic and Statistical Manual of Mental Disorders- $I V^{30}$ criteria 
for major depression and even more present depressive manifestations. Contemporary evidence has also noted elevated health care expenses, poor quality of life, deprived adherence to therapy, and two times greater the mortality rate within depressed patients who experience clinical manifestations of CAD, such as myocardial infarction. However, the diagnosis, and subsequent treatment, of depression among CAD patients has been suboptimal despite this high prevalence. To attend this dilemma further, the American Heart Association (AHA) has recently published a science advisory for clinicians, which recommends routine screening for depression in CAD patients. ${ }^{31}$ The American Psychiatric Association endorsed this advisory.

The Patient Health Questionnaire (PHQ-2) ${ }^{32}$ offers two queries that are suggested for identifying depressed patients. If the answer is "yes" to one or both of the questions, it is recommended that $\mathrm{PHQ}-9^{33}$, which contains nine questions, should be made available. The PHQ-9 is a concise depression-screening tool. The majority of the patients are capable of answering completely in at least five minutes, without assistance. It provides a conditional diagnosis of depression as well as the severity stratification, which is helpful for treatment selection and monitoring.

Follow-up during a succeeding appointment is counseled for patients with mild manifestations. In patients with elevated scores, a review with a qualified professional should be done. However, it is important to point out that depressive symptoms may be present due to the complexity of the medical condition.

The current AHA advisory is very much related to the rationale expanded by the MacArthur Initiative on Depression and Primary Care ${ }^{34}$ which offers information for the recognition and management of depression in primary care settings for depression screening and care guidelines for cardiologists. ${ }^{35}$

Patients with high screening scores in the PHQ-9 query (score of 10 or higher) should be referred for a more comprehensive clinical evaluation. During this evaluation, the presence of other mental disorders (eg, anxiety and irritability) should be investigated, which have also been shown to be associated with adverse outcomes in cardiac patients. ${ }^{36}$ PHQ-2, PHQ-9 and other details can be analyzed in the following link. http://circ.ahajournals.org/cgi/ reprint/118/17/1768.pdf

With the aim of facilitating diagnosis of depression in CAD patients, some authors proposed changes in diagnostic criteria. Cavanaugh ${ }^{37}$ suggested additional criteria that would be more effective in this group of patients, such as hopelessness, loss of interest particularly for people, poor adherence to treatment, recurrent thoughts of death related to depressive symptoms, and recurrent thoughts of recovery from clinical condition below the expected.

\section{In-hospital depression}

Evaluating patients with acute myocardial infarction still in hospital, Lesperance et $\mathrm{al}^{38}$ found that sadness was the most specific symptom in patients previously depressed and was not a common complaint in patients with CAD without previous diagnosis of depression. Another interesting fact is that depressed patients complained less of lack of interest than sadness. In addition, fatigue was significantly more frequent in depressed (71\%) than in non-depressed (23\%) patients. Therefore, before attributing fatigue solely to heart disease, the cardiologist should evaluate the patient with attention to rule out the possibility of depression. On the other hand, symptoms like sleep disturbances and changes in appetite had little importance in differentiating depressed from nondepressed CAD patients. Problems with sleep and appetite are very common in both conditions.

\section{Other emotional disorders}

Other very frequent symptoms present in patients with CAD are anger/hostility, which may confound the diagnosis of depression. ${ }^{39}$ Attention should be given to a patient with anger/hostility, making the diagnosis of either depression and/or CAD difficult. In the presence of an irritable mood, such as anger/hostility, it is very important that the cardiologist actively investigate other symptoms of depression. In a recent publication, Chida and Steptoe ${ }^{40}$ report, on a meta-analysis of prospective studies, a $20 \%$ increased risk of both incident $\mathrm{CAD}$ in initially healthy individuals and poor prognosis in CAD patients.

Sudden strong emotional stress can lead to transient and reversible left ventricular dysfunction, even in individuals without coronary disease, an effect that may be mediated by elevated plasma catecholamine levels. ${ }^{41}$ The chest pain and electrocardiographic findings simulate an acute myocardial infarction with ST segment elevation. Normal coronary arteries in the angiogram are characteristic of this condition, denoted cardiomyopathy by stress. Examples of emotional stress are generally related to a strong abhorring; sometimes for loss of a close relative. The emotional impact felt is of such magnitude that this frame was popularly known as "brokenhearted". This condition is more common among women aged 40 to 50 years. The Japanese described this phenomenon in the left ventricle as "tako tsubo", coming from the fishing net used in regional fishing of octopus (Figure 2). 
A

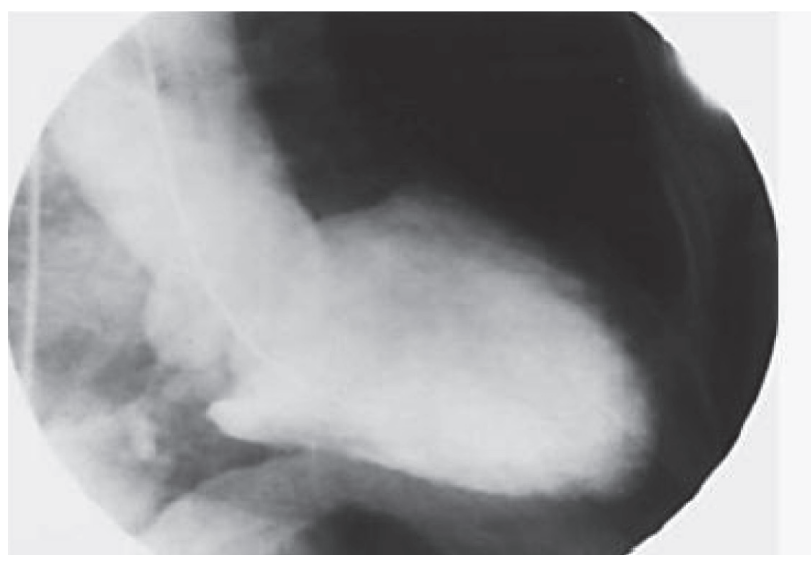

B

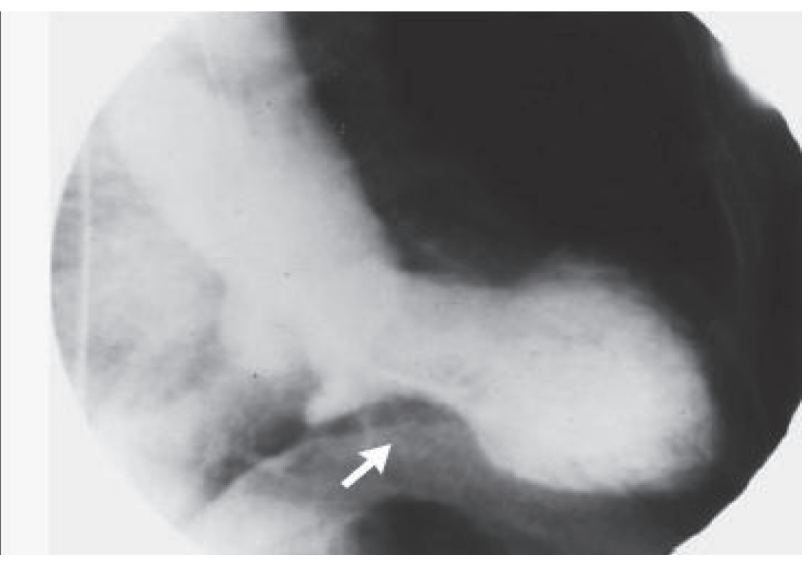

Figure 2 Ventriculography of the left ventricle in a patient with cardiomyopathy stress. ${ }^{41}$ Panel $\mathbf{A}$ shows diastole and panel B shows systole. Observe akinesia in the apical and the middle region of the left ventricle; the base is spared confirming good contractility (shaft).

\section{Conclusion}

Numerous investigations strongly point out that depression is a significant and independent risk factor for CAD in both non$\mathrm{CAD}$ and CAD patients, with a relative risk of about 2.0. It is possible that depression is merely a psychosocial risk factor, such as others like anger, hostility, stress, and anxiety.

Difficulties in distinguishing depression from CAD symptoms may lead to misdiagnosis and inadequate management of these two conditions. Patients with heart disease must be evaluated in detail in order to differentiate depression from the symptoms related to heart disease in general. Many patients with cardiovascular disease will encounter mild depression that is not easy to distinguish from a normal grief response to the diagnosis of a significant illness, while many others will experience moderate to severe depression.

Several reasonable biobehavioral mechanisms for which preliminary support exists, including treatment adherence, lifestyle factors, traditional risk factors including platelet reactivity, HPA and SAM axis imbalance, and inflammation. Recent publications suggest the role of a polymorphism in the promoter region of the gene 5-HTTLPR in predisposing depression.

\section{Disclosure}

The authors report no conflicts of interest in this work.

\section{References}

1. Thombs BD, Bass EB, Ford DE, et al. Prevalence of depression in survivors of acute myocardial infarction. J Gen Intern Med. 2006;21: 30-38.

2. Bush DE, Ziegelstein RC, Tayback M, et al. Even minimal symptoms of depression increase mortality risk after acute myocardial infarction. Am J Cardiol. 2001;88:337-341.
3. Carney RM, Freedland KE, Sheline YI, Weiss ES. Depression and coronary heart disease: a review for cardiologists. Clin Cardiol. 1997; 20:196-200.

4. American Heart Association. 2001 Heart and Stroke Statistical Update. Dallas, TX: American Heart Association; 2001.

5. Musselman DL, Evans DL, Nemeroff CB. The relationship of depression to cardiovascular disease: epidemiology, biology, and treatment. Arch Gen Psychiatry. 1998;55:580-592.

6. Rozanski A, Blumenthal JA, Kaplan J. Impact of psychological factors on the pathogenesis of cardiovascular disease and implications for therapy. Circulation. 1999;99:2192-2217.

7. O'Keefe JH, Carter MD, Lavie CJ. Primary and secondary prevention of cardiovascular diseases: a practical evidence-based approach. Mayo Clin Proc. 2009;84:741-757.

8. Frasure-Smith N, Lesperance F, Prince RH, et al. Randomized trial of home-based psychosocial nursing intervention for patients recovering from myocardial infarction. Lancet. 1997;350:473-479.

9. Wells KB, Burnam MA, Rogers W, et al. The course of depression in adult outpatients. Results from the Medical Outcomes Study. Arch Gen Psychiatry. 1992;49:788-794.

10. Andrei AM, Fráguas R Jr. Cardiopatias e doenças psiquiátricas. In: Serrano Jr CV, Stefanini E, Timerman A. Tratado de Cardiologia SOCESP. 2nd ed. São Paulo, Brazil: Editora Manole; 2008:2387-2403.

11. Joynt KE, Whellan DJ, O'Connor CM. Depression and cardiovascular disease: mechanisms of interaction. Biol Psychiatry. 2003;54: 248-261.

12. McDermott MM, Schmitt B, Wallner E. Impact of medication nonadherence on coronary heart disease outcomes: a critical review. Arch Intern Med. 1997;157:1921-1929.

13. Glassman AH, Helzer JE, Covey LS, et al. Smoking, smoking cessation, and major depression. JAMA. 1990;264:1546-1549.

14. Camacho TC, Roberts RE, Lazarus NB, Kaplan GA, Cohen RD. Physical activity and depression: evidence from the Alameda County Study. Am J Epidemiol. 1991;134:220-231.

15. Pozuelo L, Tesar G, Zhang J, Penn M, Franco K, Jiang W. Depression and heart disease: what do we know, and where are we headed? Cleve Clin J Med. 2009;76:59-70.

16. Curtis BM. Autonomic tone as a cardiovascular risk factor: the dangers of chronic fight or flight. Mayo Clin Proc. 2002;77:45-54.

17. Carney RM, Saunders RD, Freedland KE, Stein P, Rich MW, Jaffe AS. Association of depression with reduced heart rate variability in coronary artery disease. Am J Cardiol. 1995;76:562-564.

18. Gehi A, Mangano D, Pipkin S, Browner WS, Whooley MA. Depression and heart rate variability in patients with stable coronary heart disease: findings from the Heart and Soul Study. Arch Gen Psychiatry. 2005; 62:661-666. 
19. Laghrissi-Thode F, Wagner WR, Pollock BG, Johnson PC, Finkel MS. Elevated platelet factor 4 and beta-thromboglobulin plasma levels in depressed patients with ischemic heart disease. Biol Psychiatry. 1997; 42:290-295.

20. Serebruany VL, Glassman AH, Malinin AI, et al. Platelet/endothelial biomarkers in depressed patients treated with the selective serotonin reuptake inhibitor sertraline after acute coronary events: the Sertraline AntiDepressant Heart Attack Randomized Trial (SADHART) Platelet Substudy. Circulation. 2003;108:939-944.

21. Sherwood A, Hinderliter AL, Watkins LL, Waugh RA, Blumenthal JA. Impaired endothelial function in coronary heart disease patients with depressive symptomatology. J Am Coll Cardiol. 2005;46: 656-659.

22. Otte C, Neylan TC, Pipkin SS, Browner WS, Whooley MA. Depressive symptoms and 24-hour urinary norepinephrine excretion levels in patients with coronary disease: findings from the Heart and Soul Study. Am J Psychiatry. 2005;162:2139-2145.

23. Whooley MA, Caska CM, Hendrickson BE, Rourke MA, Ho J, Ali S. Depression and inflammation in patients with coronary heart disease: findings from the Heart and Soul Study. Biol Psychiatry. 2007; 62: 314-320.

24. Empana JP, Sykes DH, Luc G, et al. Contributions of depressive mood and circulating inflammatory markers to coronary heart disease in healthy European men: the Prospective Epidemiological Study of Myocardial Infarction (PRIME). Circulation. 2005;111:2299-2305.

25. Frasure-Smith N, Lesperance F, Irwin MR, Sauve C, Lesperance J, Theroux P. Depression, C-reactive protein, and two-year major adverse cardiac events in men after acute coronary syndromes. Biol Psychiatry. 2007;62:302-308.

26. Tracey KJ. Physiology and immunology of the cholinergic antiinflammatory pathway. J Clin Invest. 2007;117:289-296.

27. Nakatani D, Sato H, Sakata Y, et al. Influence of serotonin transporter gene polymorphism on depressive symptoms and new cardiac events after acute myocardial infarction. Am Heart J. 2005;150:652-658.

28. Jiang W, Alexander J, Christopher E, et al. Relationship of depression to increased risk of mortality and rehospitalization in patients with congestive heart failure. Arch Intern Med. 2001;161:1849-1856.

29. Frasure-Smith N, Lesperance F. Depression and cardiac risk: present status and future directions. Postgrad Med J. 2010;86:193-196.
30. American Psychiatric Association. Diagnostic and Statistical Manual of Mental Disorders, Fourth Edition, Text Revision (DSM-IV-TR). 4th ed. Washington, DC: American Psychiatric Association; 2000.

31. Lichtman JH, Bigger JT, Blumenthal JA, et al. Depression and coronary heart disease. Recommendations for screening, referral, and treatment. A science advisory from the American Heart Association Prevention Committee of the Council on Cardiovascular Nursing, Council on Clinical Cardiology, Council on Epidemiology and Prevention, and Interdisciplinary Council on Quality of Care and Outcomes Research. Circulation. 2008;118:1768-1775.

32. Whooley MA, Simon GE. Managing depression in medical outpatients. N Engl J Med. 2000;343:1942-1950.

33. The MacArthur Initiative on Depression and Primary Care. Patient health questionnaire tool kit for clinicians. 2003. Available from: http:// www.depression-primarycare.org/clinicians/toolkits/materials/forms/ phq9. Accessed Sep 12, 2008.

34. US Preventive Services Task Force. Screening for Depression: Recommendations and Rationale. Rockville, MD: Agency for Healthcare Research and Quality; 2002.

35. US Preventive Services Task Force. Screening for depression: recommendations and rationale. Ann Intern Med. 2002;136:760-764.

36. Strik JJ, Denollet J, Lousberg R, Honig A. Comparing symptoms of depression and anxiety as predictors of cardiac events and increased health care consumption after myocardial infarction. J Am Coll Cardiol. 2003;42:1801-1807.

37. Cavanaugh SV. Diagnosing depression in the hospitalized patient with chronic medical illness. J Clin Psychiatry. 1984;45:13-17.

38. Lesperance F, Frasure-Smith N, Talajic M. Major depression before and after myocardial infarction: its nature and consequences. Psychosom Med. 1996;58:99-110.

39. Denollet J, Pedersen SS. Anger, depression, and anxiety in cardiac patients: the complexity of individual differences in psychological risk. J Am Coll Cardiol. 2009;53:947-949.

40. Chida Y, Steptoe A. The association of anger and hostility with future coronary heart disease: a meta-analytic review of prospective evidence. J Am Coll Cardiol. 2009;53:936-946.

41. Wittstein IS, Thiemann DR, Lima JAC, et al. Neurohumoral features of myocardial stunning due to sudden emotional stress. N Engl J Med. 2005;352:539-548.
Vascular Health and Risk Management

\section{Publish your work in this journal}

Vascular Health and Risk Management is an international, peerreviewed journal of therapeutics and risk management, focusing on concise rapid reporting of clinical studies on the processes involved in the maintenance of vascular health; the monitoring, prevention and treatment of vascular disease and its sequelae; and the involvement of

\section{Dovepress}

metabolic disorders, particularly diabetes. This journal is indexed on PubMed Central and MedLine. The manuscript management system is completely online and includes a very quick and fair peer-review system, which is all easy to use. Visit http://www.dovepress.com/ testimonials.php to read real quotes from published authors. 